\title{
Lugares de memória e ressignificação cultural na Terra Indígena Toldo Pinhal
}

\section{Places of memory and cultural re-signification in the Indigenous Land of Toldo Pinhal}

\author{
Jéssica Alberti Giaretta ${ }^{1}$ \\ Jaisson Teixeira Lino $^{2}$
}

\begin{abstract}
Resumo: O presente artigo tem por objetivo apresentar alguns aspectos culturais fundamentais para a consecução da demarcação da Terra Indígena Toldo Pinhal, localizada no município de Seara, na região oeste de Santa Catarina. Utilizando-se de variadas fontes bibliográficas e audiovisuais, reflete-se aqui sobre os elementos identitários culturais que foram acionados pela referida comunidade indígena na luta pela afirmação de direitos básicos, como o acesso à terra e a manutenção de traços culturais críticos para a manutenção do "ser Kaingang". Deste modo, apresentam-se lugares de memória distribuídos na paisagem juntamente com demais atividades culturais, com destaque para as semanas culturais. Por fim, reafirma-se que a mobilidade territorial é parte de um todo cultural deste povo, contrariando as ideias de parte dos não-indígenas que associam "nomadismo" com "ausência de apego a terra".
\end{abstract}

Palavras-Chave: história indígena, Kaingang, terra indígena, lugares de memória.

\begin{abstract}
The present paper has as its objective to show some fundamental cultural aspects to achievement of demarcation of Indigenous Land Toldo Pinhal, located on the city of Seara, in the west of Santa Catarina, Brasil. It reflects here the cultural identities elements that were added by the referred indigenous community in the struggle for the affirmation of the basic rights, as the access to the land and the maintenance of critical cultural traits of "being Kaingang". In this way, are introduced memory places in the landscape together with other cultural aspects, with notability to the cultural weeks activities. Lastly, it reassures that the territorial mobility is part of the culture of this people, opposing the idea that non-indigenous people associate with "nomadism" with " lack of feelings with the land".
\end{abstract}

Key Words: indigenous history, Kaingang, indigenous land, places of memory,

\section{Introdução}

\footnotetext{
${ }^{1}$ Graduada em História pela Universidade Federal da Fronteira Sul (UFFS), campus Chapecó/SC.

Email: jeh.giaretta@hotmail.com

${ }^{2}$ Professor da Universidade Federal da Fronteira Sul (UFFS), campus Chapecó/SC. Pós-doutor em Arqueologia pela Universidade de Amsterdã, Holanda. Email: lino@uffs.edu.br.
} 
Pensado com intuito de abordar aspectos relacionados à formação do discurso pró-índio formulado no decorrer do processo de demarcação das terras da TI Toldo Pinhal, o artigo busca desenvolver um diálogo entre a memória do povo indígena Kaingang residente da TI e a historicidade que ela proporciona para a legitimidade da posse das terras. Nesta perspectiva, serão abordados tópicos fundamentais para definição da memória bem como o papel que ela desempenha na construção dos argumentos indígenas para dar sustentação à sua vontade/necessidade pela recuperação do território. Partindo deste ponto, o conhecimento adquirido em Michael Pollak (1989) permite pontuar que há um sentimento de pertencimento e que a memória é utilizada como forma de identificação, ao que é comum para determinado grupo e o que o diferencia de outros.

Para além desta abordagem, o texto reafirma a importância da tradição indígena Kaingang, a qual se mostra relevante para o povo do Toldo Pinhal. Sendo necessário desenvolver a compreensão com relação à mobilidade deste grupo, buscou-se uma abordagem histórica para compreender como os povos indígenas se movem. Neste aspecto, é fator determinante o não acúmulo de bens, tido como diferenciação de outros grupos, o que facilita o processo de mudança. Esta prática gera em muitos momentos um debate acerca da demarcação de terras, onde os povos não indígenas questionam e criticam negativamente esta mobilidade.

\section{A busca pelos Lugares de Memória}

Falar sobre memória é como ir a fundo em um sentimento individual ou coletivo. Está atrelada às lembranças, o que vem do interior de uma determinada pessoa ou grupo, permite manter certas informações que são constantemente repassadas e repensadas. Segundo Jacques Le Goff (2003), a conservação da memória, sobretudo a memória coletiva, exerce papel fundamental no diálogo do tempo e a história, configurando-se como um dos pilares da própria história, tendo sido recentemente reconhecida como um importante objeto de debate historiográfico.

No caso do presente estudo, ao trabalhar a memória Kaingang na retomada da Terra Indígena Toldo Pinhal, é preciso e possível compreendê-la a partir da definição de Michel Pollack, segundo o qual a memória de um determinado grupo diz respeito ao seu sentimento de pertencimento e também de reconhecimento identitário. A memória permite que o povo se reconheça mediante ela. Portanto, "ao definir o que é comum a um grupo e o que, diferencia dos outros, fundamenta e reforça os sentimentos de pertencimento e as fronteiras socioculturais" (POLLAK, 1989, p.3). 
Ao encontro deste debate, é possível visualizar de acordo com Pierre Nora que a memória é um evento atual e representa sempre uma ligação do passado com o presente, por isso afirma que

A memória é a vida, sempre carregada por grupos vividos e, nesse sentido, ela está em permanente evolução, aberta à dialética da lembrança e do esquecimento, inconsciente de suas deformações sucessivas, vulnerável a todos os usos e manipulações, susceptível de longas latências e de repentinas revitalizações (NORA, 1993, p.9).

A memória se constitui, para a análise do processo de retomada da Terra Indígena Toldo Pinhal, como um argumento de sustentação no discurso pró-índio. Pontuando que neste contexto, o discurso possui uma ideologia, que a partir da fala produz um significado histórico de grande relevância para a população indígena. O discurso, de acordo com Kalina Silva e Maciel Silva (2009) é capaz de construir relações entre o sujeito e o objeto que ele representa, assim, os indígenas na condição de sujeitos e a sua memória como objeto.

Como forma de garantir a demarcação da terra, o povo indígena precisou provar sua existência no território, ou seja, comprovar que eles viveram neste local antes mesmo da chegada da colonização por meio das companhias colonizadoras Rio Branco e Luce \& Rosa. Uma estratégia adotada por eles foi usufruir dos lugares de memória identificados pelos indígenas no período anterior a colonização por volta dos anos 1930. Entendendo a relevante influência destes lugares a partir de Pierre Nora (1993), pois "a curiosidade pelos lugares onde a memória se cristaliza e se refugia está ligada a este momento particular da nossa história”. Isto é, o reconhecimento dos lugares de memória estabelece uma conexão direta com o discurso pró demarcação e o momento anterior ao contato em que os indígenas estavam presentes no território reivindicado.

No entanto, é preciso enfatizar que os povos indígenas têm o direito às terras asseguradas por lei. Essa afirmação se sustenta, pois, a partir da Constituição Federal Brasileira de 1988, logo nos primeiros parágrafos do artigo 231, estabelece-se que "são terras tradicionalmente ocupadas pelos índios as por eles habitadas em caráter permanente" (BRASIL, 1988, p. 133). Por isso, compreende-se que essas populações são originárias e que habitaram a terra antes mesmo do que qualquer outro grupo étnico, o que também os dá a garantia de possuir uma memória viva.

Partindo da compreensão em Pierre Nora de que há uma reciprocidade entre a memória e a história, é possível afirmar que os lugares de memória se constituem em lugares de história, pois eles "garantem ao mesmo tempo a cristalização da lembrança e sua transmissão" (NORA, 1993, p.7). Portanto, os lugares de memória são fatores que atuam ativamente na permanência da história do povo indígena e são pontuados, a partir do estudo das fontes como, o conhecimento da mata, das plantas medicinais, das frutas, os rios que provinham a pesca e principalmente os 
cemitérios. Torna-se evidente a importância de sua utilização mediante fala proferida por Orides Cavalheiro retirada do documentário "Herdeiros da Teimosia" (2015)

Antigamente tinha desde os lajeados né, os rios por exemplo, a pesca. Aonde o nosso povo ia pescar. Os cemitérios antigos, em vários locais onde o nosso povo era enterrado. Aonde caçava, aonde pescava, aonde morreu o cacique Gregório, aonde ele fez a fogueira das taquaras. Aonde tinha mamão que gostavam de comer, aonde tinha frutas, pinhão, tatu e o caminho das antas. Os paris (armadilha pra pesca) aonde tinha e pescava com o cipó que intoxica o peixe (CAVALHEIRO, 2015).

O cemitério indígena se configura como um dos lugares de memória mais importantes para a comprovação da existência da população Kaingang neste espaço. O momento da morte de um integrante do grupo é visto pelo mesmo como uma passagem no qual o espírito deixa o corpo e segue o Numbê, aldeia dos mortos, de acordo com Juracilda Veiga (2006), o ritual da passagem é um dos mais significativos dentro da cultura Kaingang.

A leitura em Veiga (2006) nos possibilita a compreensão de que os indígenas creem que o Numbê "fica no poente e por esta razão os mortos devem ser enterrados com a cabeça para Leste e o rosto voltado para Oeste". Além disso, os ritos do luto eram/são muito respeitados, acreditam que a alma da pessoa que morre não deixa o espaço dos vivos de imediato e por isso, deve-se tomar cuidado com as pessoas próximas de quem morreu, principalmente cônjuges e filhos. "A casa pode ser pintada de preto. Colocam-se ramos de uma planta chamada kiprer nos lados da porta da casa e realiza-se um rito de luto" (VEIGA, 2006, p. 175).

A partir do laudo antropológico realizado por Wagner de Oliveira no ano de 1993 (OLIVEIRA, 1993), percebe-se que o culto aos mortos se configurou como um dos eventos passíveis de reunir o maior número da população indígena na TI Toldo Pinhal. Fica evidente pelos relatos do colono Guilherme Moeller, contidos no laudo, que a morte do Cacique Gregório Rodrigues, pai de João Maria, por volta dos anos 1930 foi motivo para que os colonos pudessem ver o povo indígena em grande número reunido para o ritual de passagem.

Além disso, utiliza-se da memória para a partir da visualização do documentário "O voo Solitário" (Direção de Chico Faganello) de 1991 entender que ela vive juntamente com a história da população Kaingang, onde o próprio João Maria Rodrigues faz um relato sobre a morte de seu pai,

Meu pai, o cacique dos índios está sepultado aqui nesta terra. A morte dele foi feita pela mão de um tigre. O tigre pegou a porca do meu avô. E no outro dia eles armaram uma espingarda, uma 16. E o tigre de noite, veio e estourou a espingarda. $\mathrm{O}$ tigre saiu machucado, mas não ficou no lugar. No outro dia eles soltaram os cachorros atrás. E aí, acuaram o tigre. E o meu pai era o mais ligeiro no mato, correu na frente e chegou na frente dos outros rapazes. E aí, o cachorro tava acuando o tigre debaixo de uma madeira. Caído. Madeira grossa. Daí... subiu por cima da madeira para tirar o tigre, e nisso ele resvalou numa casca da madeira e caiu lá junto com o tigre (RODRIGUES, 1991). 
João Maria Rodrigues, o "Cacique Teimoso", nasceu no ano de 1915 e faleceu em 1996 e também se encontra enterrado na TI, próximo a seu pai. Junto ao seu sepultamento, há uma árvore de cedro que pelo estudo da memória indígena encontrado nas fontes, é possível compreender que a população Kaingang costuma confeccionar uma cruz com esta madeira para identificar o túmulo de seus líderes. A árvore brota e ganha destaque dentro do cemitério indígena, representando a proteção de seus ancestrais para todo o seu povo. No cemitério da TI deste estudo há dois cedros que permitem localizar e destacar os sepultamentos de João Maria e de seu pai, o cacique Gregório.

Figura 01: Cemitério Kaingang localizado na TI Toldo Pinhal.

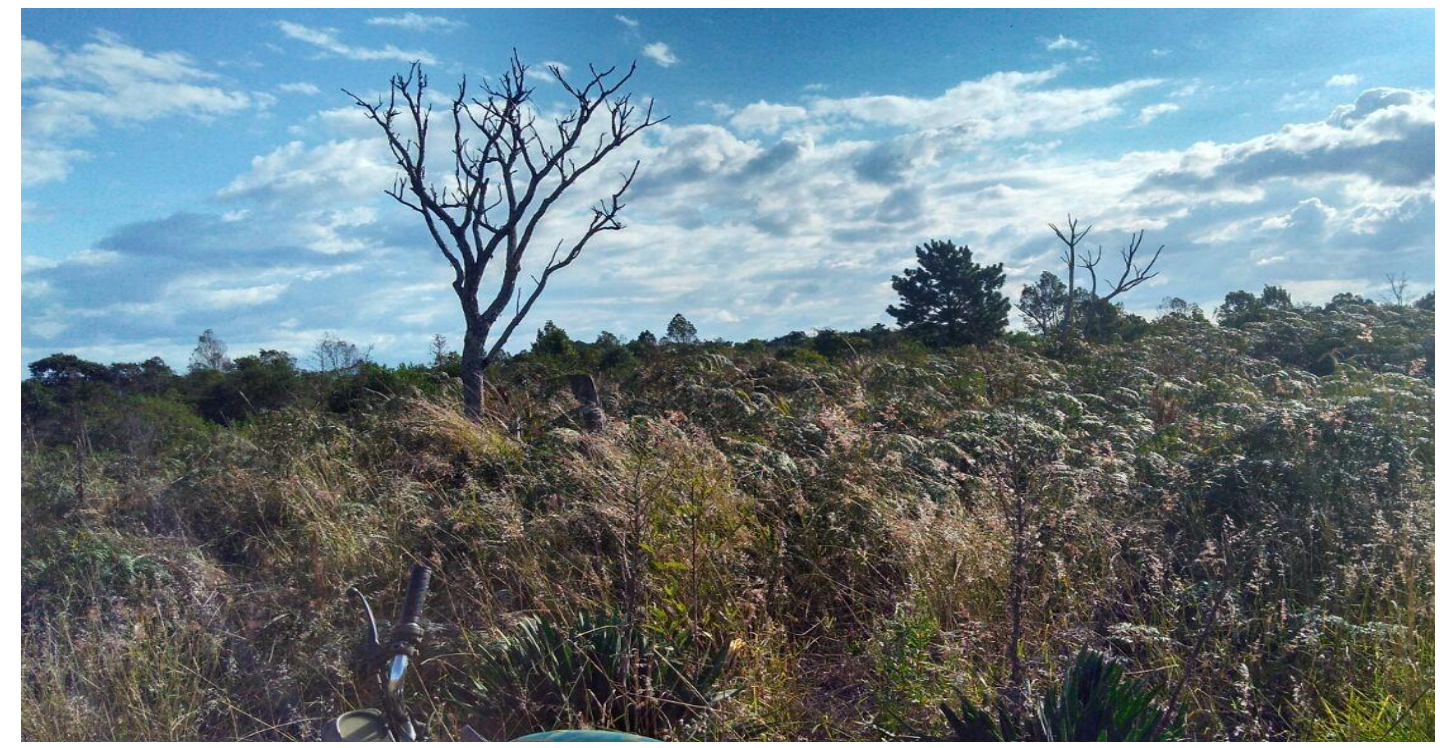

Fonte: acervo Jessica A. Giaretta

Figura 02: Sepultamento do líder João Maria Rodrigues, o "Cacique Teimoso". 


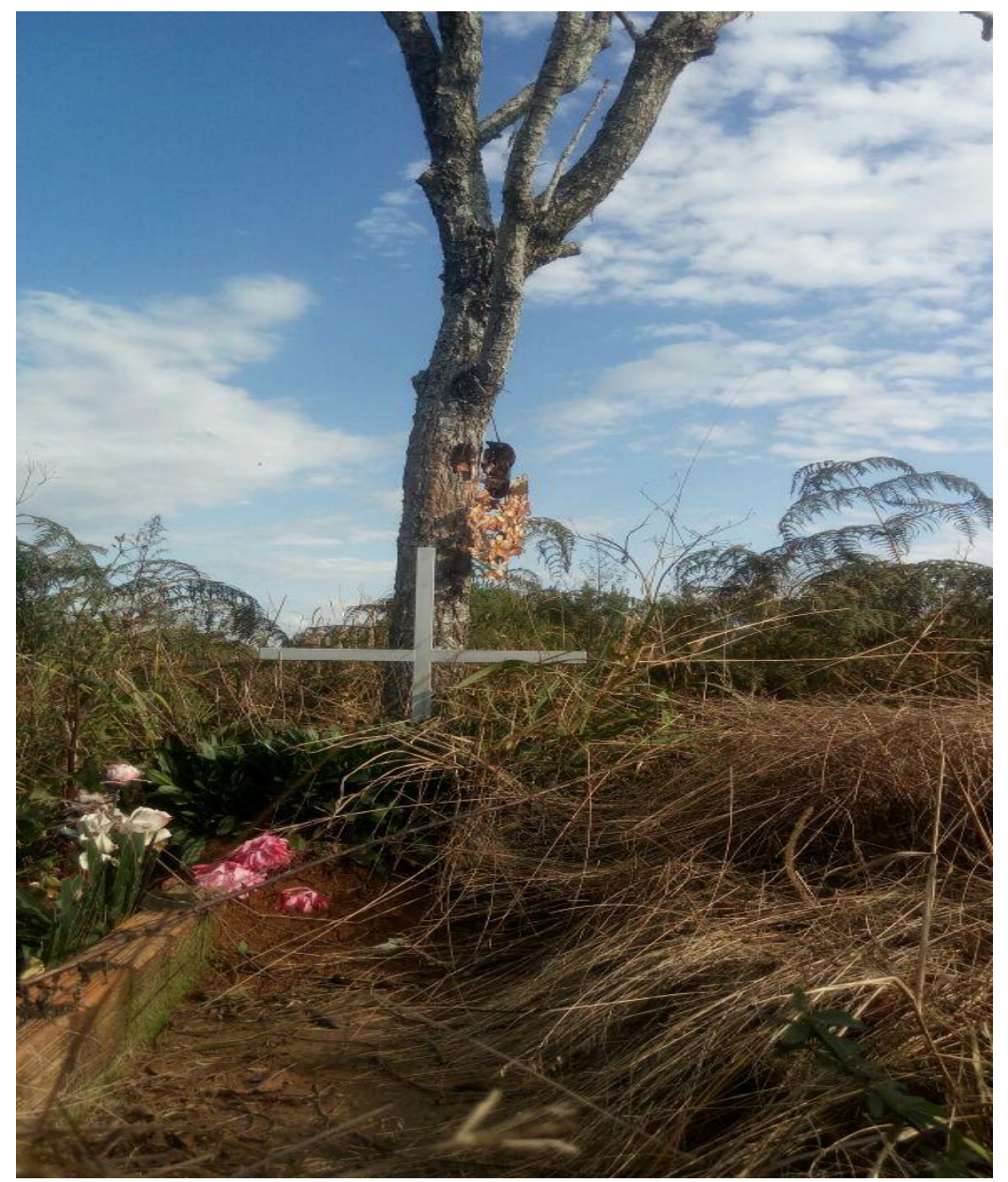

Fonte: acervo Jessica A. Giaretta

De acordo com o laudo antropológico de identificação e delimitação da TI Toldo Pinhal, elaborado por Wagner de Oliveira (1993), João Maria liderou a resistência contra o avanço colonizador, ao negar-se abandonar a área original da TI Toldo Pinhal. Ainda de acordo com esta fonte, o mesmo permaneceu na teimosia e que não deixaria a terra na qual seu cordão umbilical estava enterrado. Essa atitude se justifica, pois, os Kaingang enterravam os cordões umbilicais produzindo uma relação com a terra, representando uma conexão com seus ancestrais: "é certo que atribuíam e ainda atribuem grande importância ao destino dado ao cordão umbilical, à ponto de referirem-se com nostalgia à terra ou a aldeia ontem têm seus umbigos enterrados" (VEIGA, 2006, p. 27).

Todos os argumentos apresentados com relação à memória da população Kaingang da Terra Indígena Toldo Pinhal bem como a identificação dos lugares de memória, proporciona um caminho para o entendimento de que a liberação da área ocorreu de forma legítima.

\section{A importância da ressignificação e valorização da cultura Kaingang}


Os povos indígenas são dotados de muitas crenças e mitos, estes se reportam à origem dos grupos, aos traços corporais, à organização social e política, à formação da terra, do céu e dos seres. O povo Kaingang, possui em seu mito fundador a crença de que se originaram dos dois irmãos chamados Kamé e Kanhru. Veiga recuperou o relato do antropólogo Curt Unkel Nimuendajú sobre este mito.

A tradição dos Kaingang conta que os primeiros desta nação saíram do chão (...). Saíram em dois grupos, chefiados por dois irmãos por nome de Kañerú e Kamé, sendo que aquele saiu primeiro. Cada um já trouxe um número de gente de ambos os sexos. Dizem que Kañerú e sua gente toda eram de corpo fino, peludo, pés pequenos, ligeiros tanto nos seus movimentos como nas suas resoluções, cheios de iniciativa, mas de pouca persistência. Kamé e seus companheiros, ao contrário, eram de corpo grosso, pés grandes, e vagarosos nos seus movimentos e resoluções (VEIGA, 2006, p.81).

O mito fundador dos dois irmãos resultou na divisão do povo Kaingang em duas metades exogâmicas, Kamé e Kairu que são determinantes da vida social e cultural do grande grupo. Para Veiga (2006, p.81) “essa divisão é o aspecto fundamental da organização social dos Kaingang que se opõe e se complementam", ou seja, ocorre uma divisão/ separação, porém ao mesmo tempo uma união dos dois grupos, sendo que um necessita do outro. A partir delas se movem relações internas como os casamentos, uma vez que, de acordo com Nacke (2007) inicialmente eles apenas eram realizados entre os membros de metades opostas.

Quanto à escolha de um nome para uma criança Kaingang, deve-se levar em conta alguns fatores no momento de seu nascimento. A leitura em Veiga (2006, p.145) nos possibilita afirmar que escolher um nome Kaingang é um ato dotado de significação para a cultura deste povo, “eles acreditam que o ser humano é formado do organismo e do espírito, sendo este último relacionado ao nome. Idealmente a constituição física e nome (espírito-caráter) devem coincidir”. Na TI Toldo Pinhal, as crianças recebem um nome em língua portuguesa e um nome na língua Kaingang, o que está relacionado principalmente com fenômenos da natureza ou nomes de animais. Esta afirmação se baseia na visualização do documentário Herdeiros da Teimosia (2015), uma vez que logo nas primeiras cenas, as crianças mencionam e brincam com seus nomes indígenas.

Um aspecto importante a ser abordado trata das marcas relativas para cada uma das metades. O grupo Kamé é identificado por marcas compridas em forma de riscos, já os Kairu por marcas redondas em forma de pontos. Veiga (2006) identifica que marcas redondas são o Leste e marcas compridas o Oeste. Essas marcas são representadas pelos indígenas a partir das pinturas corporais, as quais fazem parte da identificação da origem de cada indivíduo durante a realização dos rituais. 
Seguindo nesta linha de pensamento e análise, é possível abordar sobre um dos principais rituais desta cultura, o qual as leituras apresentam diversas nomenclaturas, chamado Kiki, Kikoia ou Veingreinyã, ritual de culto aos mortos ou ainda, rito de passagem dos mortos. A partir das observações de Wagner de Oliveira (1993) em seu Laudo Antropológico é possível afirmar que este ritual é um momento de grande expressão da cultura Kaingang, com muitas danças, festas e grande aproximação com a mãe terra, uma vez que para a realização do mesmo são utilizadas ervas e o tronco de uma araucária, especialmente escolhido e retirado do mato, com a permissão que os indígenas pedem para a natureza.

No Toldo das Lontras é que o etnólogo Robert Baldus pôde observar o Veingreinyã (o culto dos mortos, celebrado na estação propícia do milho e do pinhão), como a base e a expressão mais forte da cultura espiritual dos Kaingang, porque a vontade da comunidade no sentido da própria defesa psíquica está fundada nele e só por ocasião dele se apresenta coletivamente. Nunca a não ser no Veingreinyã, a horda se reúne tão completamente, mostrando sua organização (OLIVEIRA, 1993, p. 8).

Nacke (2007) afirma que este ritual não é praticado com tanta frequência atualmente devido a riscos, de ordem espiritual, para os participantes, caso não seja realizado de forma correta. Portanto, não há registros sobre a realização deste ritual dentro da TI Toldo Pinhal, o que não quer dizer que não tenham em algum momento ocorrido.

As proibições do Estado e a ocupação de terras originárias representaram grandes dificuldades de permanência efetiva dos rituais para os povos nativos de todo o Brasil. No entanto, embora com a dizimação do povo Kainkang por parte do processo colonizador, estes ainda se identificam como grupos indígenas, isso se dá devido à capacidade de adaptação, sendo capaz de incorporar elementos estrangeiros à sua cultura, mesmo tendo abandonado tantos outros. Esta adequação indígena foi o que proporcionou a sobrevivência de seu povo.

Portanto, para além da retomada das terras, o povo indígena Kaingang do Toldo Pinhal percebeu como necessidade de constantemente reafirmar também a cultura indígena, reaver as práticas e rituais que haviam se ausentado de sua vivência diária. Uma vez que o afastamento da população Kaingang teve como consequência a ausência da vivência da cultura no povo indígena de Linha Gramado, Rosário e Pinhal era preciso que a sua cultura pudesse sobreviver ao nevoeiro da colonização alemã e italiana proposta pelo governo brasileiro.

Com isso, é importante pontuar que a demarcação das terras não significa uma automática retomada de aspectos da cultura. Henrique Kujawa (2015) afirma que em motivo da contradição existente na efetivação das políticas territoriais indígenas, "o fato de que a simples demarcação da terra não garante necessariamente a possibilidade de desenvolvimento desses povos" (KUJAWA, 2015, p. 33). 
Fica perceptível no documentário "Herdeiros da Teimosia" o reconhecimento da lacuna que a colonização deixa em sua identidade indígena e a necessidade de reassumi-la. Percebe-se a falta sentida por eles do momento em que puderam expressar sua cultura de forma intensa e verdadeira: "não é como no passado, mas a gente não pode esquecer da nossa cultura, das nossas tradições", afirma o professor Daniel Cadete Sêm (2015). Por isso o trabalho realizado pelos membros da TI ocorre através das pinturas, da dança e do reconhecimento da importância da cultura indígena como uma forma de restabelecer e transmitir a cultura às crianças, os quais representam a continuidade da expressão cultural.

Como professor, meu objetivo é o de resgatar a cultura indígena, como eu falei, ela já está deixando para trás, então eu como os outros professores, a gente traz isso para a sala de aula. Como o aluno tem que falar, reconhecer os alfabetos em Kaingang, reconhecer a cultura Kaingang, as marcas Kaingang, as pinturas Kaingang e como o índio vive na sociedade indígena (SÊM, 2015).

Como forma de expressão cultural, o povo indígena da TI Toldo Pinhal desenvolve um evento nomeado "Saberes e Sabores". Anualmente, na semana que envolve o dia 19 de abril, dia nacional do índio, são organizadas atividades como danças, preparação de alimentos, pinturas entre outras formas de expressar a cultura Kaingang, onde os indígenas externam sua forma de vida cotidiana. Para tal, são convidadas todas as escolas e pessoas da região que tiverem interesse em vivenciar e compreender a realidade da TI. As crianças e jovens em sua maioria alunos da escola indígena Cacique Pirõy demonstram aspectos da cultura que a comunidade pensa ser importante para externalizar ao público não-indígena.

Figura 03: Integração entre alunos da escola indígena e não indígena na semana cultural "Saberes e Sabores". 


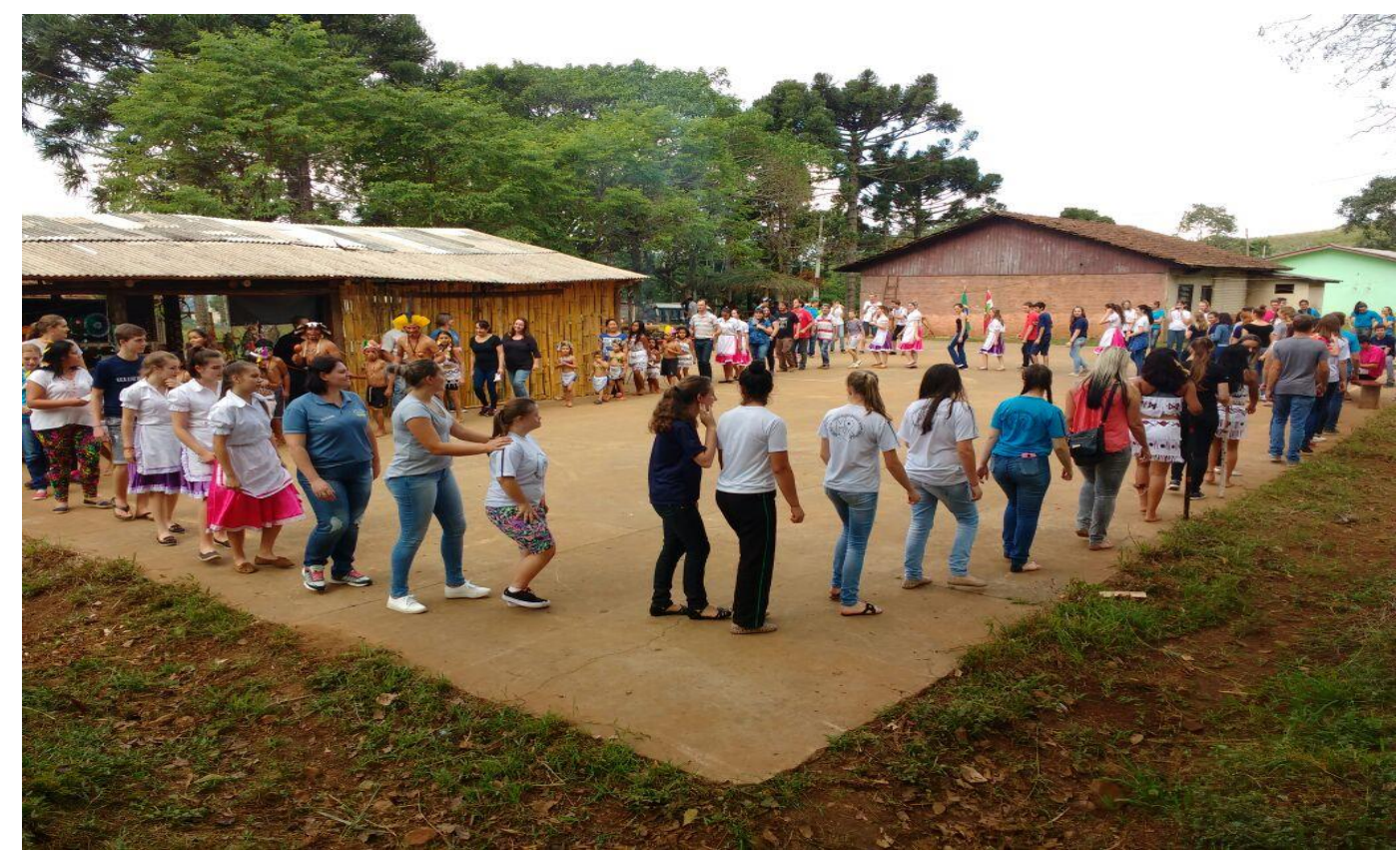

Fonte: acervo Jessica Alberti Giaretta

Figura 04: Fênvu - Inseto coletado do tronco da palmeira.

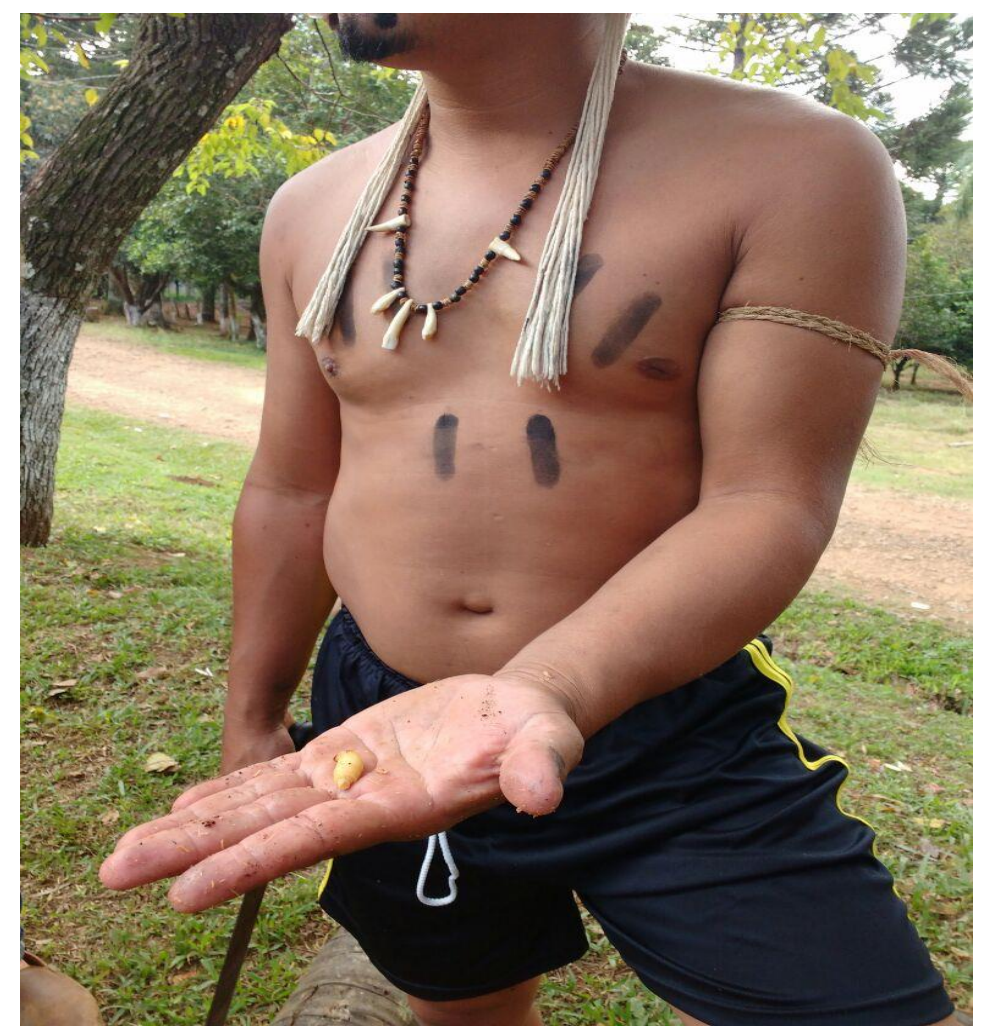

Fonte: acervo Jessica A. Giaretta

No ano de 2017, o evento contou com uma particularidade, o que pode ser avaliado como uma iniciativa positiva por parte do povo indígena. A fim de reconhecer que, embora a colonização representou um ataque à população indígena local, é importante perceber que a miscigenação simboliza a formação da identidade cultural do Oeste de Santa Catarina. 
Como forma de integração da TI perante a comunidade circundante para além de convidar professores e alunos de outras escolas, o Toldo Pinhal cedeu seu "palco" a eles, abrindo espaço para que os alunos descendentes dos colonizadores pudessem por meio de apresentações culturais demonstrar aspectos da cultura alemã e italiana da região. As pessoas que estiveram no local puderam visualizar as apresentações culturais, saborear especiarias da culinária indígena em alimentos como o bolo de aipim assado no boralho (folha de palmeira), o tatu assado o fênvu (inseto retirado do tronco da palmeira), pinhão entre outros. Além disso, ambos os grupos provaram os alimentos oriundos da culinária alemã e italiana como a cuca e o salame, levadas pelas escolas, uma vez que as mesmas tiveram o espaço para tal. Neste momento de troca cultural ficou evidente o interesse pelo reconhecimento cultural dos diferentes grupos formadores didentitários.

\section{A mobilidade do povo Kaingang e a questão da territorialidade}

A territorialidade ultrapassa o entendimento de simplesmente habitar sobre determinado espaço geográfico, ela significa uma relação de identificação com a terra e sua constituição como motivadora na formação da identidade individual e de um grupo. Por isso, em razão do pertencimento, busca-se a defesa deste território, o que também significa proteger/garantir a permanência da cultura. De acordo com Arlene Renk (com base no pensamento de Milton Santos), "a territorialidade não provém do simples fato de viver num lugar, mas da comunhão que com ele mantemos" (RENK, 2007, p.15).

Henrique Kujawa (2015) aborda sobre este tema afirmando que os conflitos se dão de forma intensa uma vez que envolvem a territorialidade dos sujeitos. Entendendo assim territorialidade como a relação que cada indivíduo ou coletividade tem com a terra.

Os povos indígenas compreendem a terra como um local onde eles podem se realizar como sociedade, sendo a terra um espaço físico e simbólico. Lappe e Laroque (2015, p.3) afirmam que "é possível perceber que o território não representa apenas uma porção física da terra, mas um espaço permeado de símbolos e significações”. Acerca do povo Kaingang os autores ainda afirmam que "o território é sagrado aos Kaingang, e o retorno aos espaços que foram habitados por seus antepassados significa a potencialização de aspectos de sua identidade étnica" (Op. cit., p. 3).

Nos anos anteriores aos do contato entre populações indígenas e colonizadores descendentes de europeus que ocuparam a região por conta da instalação de Companhias Colonizadoras na década de 1920, os povos indígenas e também os caboclos possuíam uma 
menor restrição para usufruir da terra, independente do espaço em que estavam, a isso chama-se mobilidade. No entanto, a medida que o estado brasileiro determinou os planos de colonização sobre essas terras, esta prática deixou de ser possível. Arlene Renk (2007, p. 15) critica a prática colonizadora e a questiona sobre "quando se levará em conta o desejo de mobilidade?".

O povo indígena Kaingang, independentemente de qualquer processo de demarcação de terras, possui a cultura da mobilidade. São famílias que não procuram o acúmulo excessivo de bens e sim o bem-estar no local em que vivem. Em "Herdeiros da Teimosia" (SANTOS, 2015b) há a afirmação de que "viver em diferentes terras indígenas faz parte da cultura Kaingang". As falas proferidas neste documentário possibilitam a compreensão desta prática, "o índio não tem fronteira, o índio não tem de dizer, não, eu vou ficar aqui porquê aqui é meu! [...] sim por causa que vem assim desde a época dos nossos avós né, a gente tem direito de morar aonde quiser" (SANTOS, 2015b). A ação de se deslocar de um ponto A para um ponto B reside em causas várias, que vão de razões ambientais, culturais e cosmológicas, podendo estas razões ter um caráter interno próprio da cultura e visão de mundo indígena, e externos, referentes ás pressões e conflitos interculturais advindos da colonização não-indígena.

Outro ponto passível de diálogo com esta pesquisa está relacionado com os discursos proferidos pelos não-indígenas a respeito desta mobilidade. Uma vez que as pessoas alegam o fato do indígena se mover com frequência e facilidade estar relacionado com a não necessidade de terras. Porém, é preciso analisar dois aspectos, sendo que o índio não se move para qualquer lugar e ainda que mover faz parte da cultura Kaingang.

Em extrato retirado do documentário "Herdeiros da Teimosia" pela fala do atual cacique João Maria dos Santos, pontua-se que o ato de mover está relacionado com a busca por melhores condições de vida, "é, às vezes ele tem um parente lá em outra terra indígena, e ele vai visitar aquele parente daí acha bom o lugar lá, acha bonito. Às vezes ele vai até ter um emprego melhor lá próximo e condições de vida um pouco melhor, ele muda, é dessa forma que tem acontecido" (SANTOS, 2015a).

\section{Considerações finais}

A memória da população indígena Kaingang contida nos relatos apresentados pelas fontes serviram como base para sustentação do objetivo proposto pelo trabalho. Avalia-se que o Toldo Pinhal por eles reivindicados e em processo final de demarcação faz parte da formação de sua identidade.

Com as informações abordadas neste artigo, a respeito das concepções sobre a formação da Terra Indígena Toldo Pinhal, é possível pontuar que ele se configura também como uma forma 
de expressão da vontade contida na população indígena de reviver sobre seu território e novamente desfrutar da cultura Kaingang.

Atualmente e de acordo com informação pessoal, residem na TI Toldo Pinhal por volta de 30 famílias, conduzidas pelo então cacique João Maria Gonçalves e demais lideranças da área. Os mesmos mantêm a boa relação com a natureza, as plantas e os animais. Permanecem com o cultivo de diversos alimentos, o que fazem de forma coletiva, representam parte do sustento destas famílias bem como atrelados aos momentos de caça e pesca. Muitas pessoas buscam, além disso, outras formas de sustento como o trabalho em empresas nos municípios vizinhos da área.

Todos os anos, durante a semana do índio, a população indígena realiza atividades culturais envolvendo a troca de conhecimentos com indígenas de outras áreas bem como com a população não-indígena dos municípios vizinhos, nas quais há a participação e apresentações culturais tanto por parte das escolas indígenas como não-indígenas.

Neste trabalho intentamos produzir uma breve contribuição à história indígena do oeste catarinense, sobretudo no que concerne às últimas décadas do século XX. Por meio do estudo da demarcação de um território indígena, procuramos mostrar a importância da valorização do passado dos povos indígenas da região. À luta por direitos e dignidade do povo Kaingang do Toldo Pinhal, dedicamos este trabalho.

\section{Fontes bibliográficas}

BRASIL Constituição da República Federativa do Brasil. Brasília: Editora do Senado, 1988.

FERNANDES, Ricardo Cid e PIOVEZANA, Leonel. Perspectivas Kaingang sobre o direito territorial e ambiental no Sul do Brasil. Revista Ambiente \& Sociedade, v. XVIII, n.2, 2015, p. $115-132$.

GOFF, Jacques Le. História \& Memória. Campinas: Editora da Unicamp, 2003.

KUJAWA, Herique. Conflitos territoriais envolvendo indígenas e agricultores: uma análise histórica e jurídica de políticas públicas contraditórias. Curitiba: CRV, 2015.

LAPPE, Emelí e LAROQUE, Luíz Fernando da Silva. Indígenas e Natureza: a reciprocidade entre os Kaingang e a natureza nas Terras Indígenas Por Fi Gâ, Jamã Ty Tãnh e Foxá. Desenvolvimento e Meio Ambiente, v. 34, 2015, p. 147-156.

NORA, Pierre. Entre Memória e História, a problemática dos lugares. Projeto História, v. 10, 1993, p. 7-28.

NACKE, Aneliese. Os Kaingang: passado e presente. In: NACKE, Aneliese et al. Os Kaingang no oeste catarinense. Chapecó: Argos, 2007, p. 33-42 
OLIVEIRA, Wagner. Relatório de identificação e delimitação: Área indígena Pinhal. Funai: Brasília, 1993.

POLLAK, Michael. Memória, Esquecimento, Silêncio. Estudos Históricos, vol, 2, n.3, 1989, p.315.

RENK,, Arlene. Território e Alteridade: construções sociais no oeste catarinense. In: NACKE, Aneliese et al. Os Kaingang no oeste catarinense. Chapecó: Argos, 2007, p. 15-32.

SILVA, Kalina Vanderlei; SILVA, Maciel, Henrique. Dicionário de conceitos históricos. 2. Ed., 2. Reimpressão. São Paulo: Contexto, 2009.

VEIGA., Juracilda. Revisão Bibliográfica sobre organização social Kaingang. Cadernos do CEOM v. 4, n.7, 1989, p. 259-331.

VEIGA, Juracilda. Aspectos fundamentais da cultura Kaingang. Campinas: Curt Nimuendajú, 2006.

\section{Fontes audiovisuais.}

CAVALHEIRO, Orides. Depoimento em HERDEIROS DA TEIMOSIA: A retomada do Toldo Pinhal pelo povo Kaingang. Direção: Sandra Alves, Pesquisa e produção: Alessandra Schmitt e Ana Carolina Dionísio, Roteiro: Alessandra Schmitt, Ana Carolina Dionísio e Sandra Alves. Seara SC, 2015. Duração: 17:14 min.

HERDEIROS DA TEIMOSIA: A retomada do Toldo Pinhal pelo povo Kaingang. Direção: Sandra Alves, Pesquisa e produção: Alessandra Schmitt e Ana Carolina Dionísio, Roteiro: Alessandra Schmitt, Ana Carolina Dionísio e Sandra Alves. Seara - SC, 2015. Duração: 17:14 min.

RODRIGUES, João Maria. Depoimento em O VOO SOLITÁRIO. Direção: Chico Fraganello, Imagens: Franco Ferrioli, Edição: Chico Fraganello e Franco Ferrioli. Seara - SC, 1991. Duração: 34:16 minutos.

SANTOS, João Maria dos. Depoimento em HERDEIROS DA TEIMOSIA: A retomada do Toldo Pinhal pelo povo Kaingang. Direção: Sandra Alves, Pesquisa e produção: Alessandra Schmitt e Ana Carolina Dionísio, Roteiro: Alessandra Schmitt, Ana Carolina Dionísio e Sandra Alves. Seara - SC, 2015a. Duração: 17:14 min.

SANTOS, Maria dos. Depoimento em HERDEIROS DA TEIMOSIA: A retomada do Toldo Pinhal pelo povo Kaingang. Direção: Sandra Alves, Pesquisa e produção: Alessandra Schmitt e Ana Carolina Dionísio, Roteiro: Alessandra Schmitt, Ana Carolina Dionísio e Sandra Alves. Seara - SC, 2015b. Duração: 17:14 min.

SÊM, Daniel Cadete. Depoimento em HERDEIROS DA TEIMOSIA: A retomada do Toldo Pinhal pelo povo Kaingang. Direção: Sandra Alves, Pesquisa e produção: Alessandra Schmitt e Ana Carolina Dionísio, Roteiro: Alessandra Schmitt, Ana Carolina Dionísio e Sandra Alves. Seara SC, 2015. Duração: 17:14 min.

O VOO SOLITÁRIO. Direção: Chico Fraganello, Imagens: Franco Ferrioli, Edição: Chico Fraganello e Franco Ferrioli. Seara - SC, 1991. Duração: 34:16 minutos. 